\title{
Triangular Transactions in Food Aid: Concept and Practice The example of the Zimbabwe operations
}

\author{
D. J. Shaw
}

\section{Concept}

Most food aid is provided in the form of commodities from donors in the developed countries from their own domestic production to recipient countries in the Third World. However, the advantages of obtaining food commodities from developing exporting countries for use as food aid with cash resources from donor countries, through what have come to be called 'triangular transactions', are now being recognised. ${ }^{2}$ These may be briefly summarised as follows.

First, triangular transactions can provide additional effective demand in the food exporting developing countries. This can stimulate production and support pricing policies and investment designed to increase agricultural production in the developing countries themselves.

Second, they can help promote the export of agricultural products, thereby increasing foreign exchange earnings for developing countries.

Third, they can result in more appropriate food commodities being provided as food aid in keeping with the food habits and customs of the recipients. For example, types of maize popular with rural consumers

\footnotetext{
'Senior Economist, Policy Unit, Office of Executive Director, World Food Programme. The views expressed in this article do not necessarily represent those of the World Food Programme.

${ }^{2}$ The resolution adopted by the World Food Conference in November 1974 on 'An improved policy for food aid' (Resolution XVIII) inter alia, urged all donor countries to '... provide, as appropriate, to food aid programmes additional cash resources for commodity purchases from developing countries to the maximum extent possible'. Report of the World Food Conference, Rome, 5-16 November 1974 [United Nations, New York, 1975:18]. The Guidelines and Criteria for Food Ald, unanimously agreed to by the Committee on Food Aid Policies and Programmes (CFA) of donor and recipient countries, which supervises the work of the WFP, at its seventh session in May 1979, recommend, inter alia, that 'donor countries should make efforts to provide whenever possible cash resources with a view to financing food aid through triangular transactions between themselves, developing food exporting countries and recipient countries, including coverage of the shipping costs wherever applicable, and further diversifying the varieties of food provided as aid. Such arrangements would increase the participation of developing exporting countries in providing food aid' [WFP/CFA: 7/21 Rome, June 1979; Annex IV. p 47].
}

in Africa are not readily available from the major temperate zone exporting and food aid donor countries.

Fourth, shipping arrangements can be simplified, eg when food is moved only between neighbouring countries. This can result in lower transport costs as well as savings in delivery time, which is particularly critical during emergencies.

Fifth, triangular transactions can help in improving physical distribution systems through strengthening and improving transport and logistical arrangements, and by encouraging investment in these basic facilities which might not happen otherwise. At the same time, organisational and management capacity can be improved for food management generally, including food aid, for which external training assistance may be provided.

Sixth, they can help stimulate and foster regional selfreliance and practical steps in technical and economic cooperation among developing countries through bodies such as the Technical Cooperation Development Council and Economic Cooperation Development Council. For example, the Zimbabwean maize operations described below have been a useful vehicle for testing out the plans and policies of the SADCC countries regarding regional food security.

Seventh, they can provide a focus for combined financial, technical, material and food aid support through the consortium or aid group approach by the international community, whereby aid is provided in mutually supportive ways.

\section{Scale of Transactions}

Information on commodity purchases in developing countries for food aid is incomplete. The indications are, however, that such triangular transactions have been used increasingly in recent years, particularly in order to provide relief assistance quickly for largescale emergency operations involving refugees and

Bulletin, 1983, vol 14 no 2, Institute of Development Studies, Sussex 
displaced persons. The UN/FAO World Food Programme (WFP), the food aid organisation of the United Nations system, made purchase commitments amounting to $\$ 37.6 \mathrm{mn}, \$ 117.5 \mathrm{mn}$ and $\$ 91 \mathrm{mn}$ in 1979,1980 and 1981 respectively, almost entirely in Third World countries for use as food aid.

A part of those purchases came from its own cash resources and from cash contributions to the Food Aid Convention (FAC) and the International Emergency Food Reserve (IEFR). The services and expertise of WFP was also used by other United Nations agencies and bilateral donors to make purchases on their behalf. It is WFP's policy to make such purchases in developing countries, to the extent possible and economical. The example of the Programme's purchases of maize in Zimbabwe illustrates the potential benefits that can be derived from triangular transactions.

\section{Zimbabwe Maize Operations}

WFP feels that it makes good sense to support a country in Africa which is experiencing surplus food production when so many other countries in that continent are in deficit, and at the same time, use its surplus stocks as food aid in projects designed to increase food production in deficit African countries and to contribute to the goal of regional self-reliance in food.

Two successive bumper maize crops created some unique problems for Zimbabwe - problems of a kind with which WFP is not normally associated but which point to a wider potential role in the future. While annual maize production ranged between 537,000 and 962,000 tons from $1975 / 76$ to $1979 / 80$, it reached over $2 \mathrm{mn}$ tons in 1980/81 and an estimated $1.5 \mathrm{mn}$ tons in $1981 / 82$. What was asked for was not food assistance, as food was in plentiful supply, but an effective and practical way to help reduce the substantial surplus that was putting a strain on storage facilities, which could lead to waste, and at the same time contribute to improving the country's export earnings. The Zimbabwe situation arose at a time when many neighbouring countries in Africa were faced with

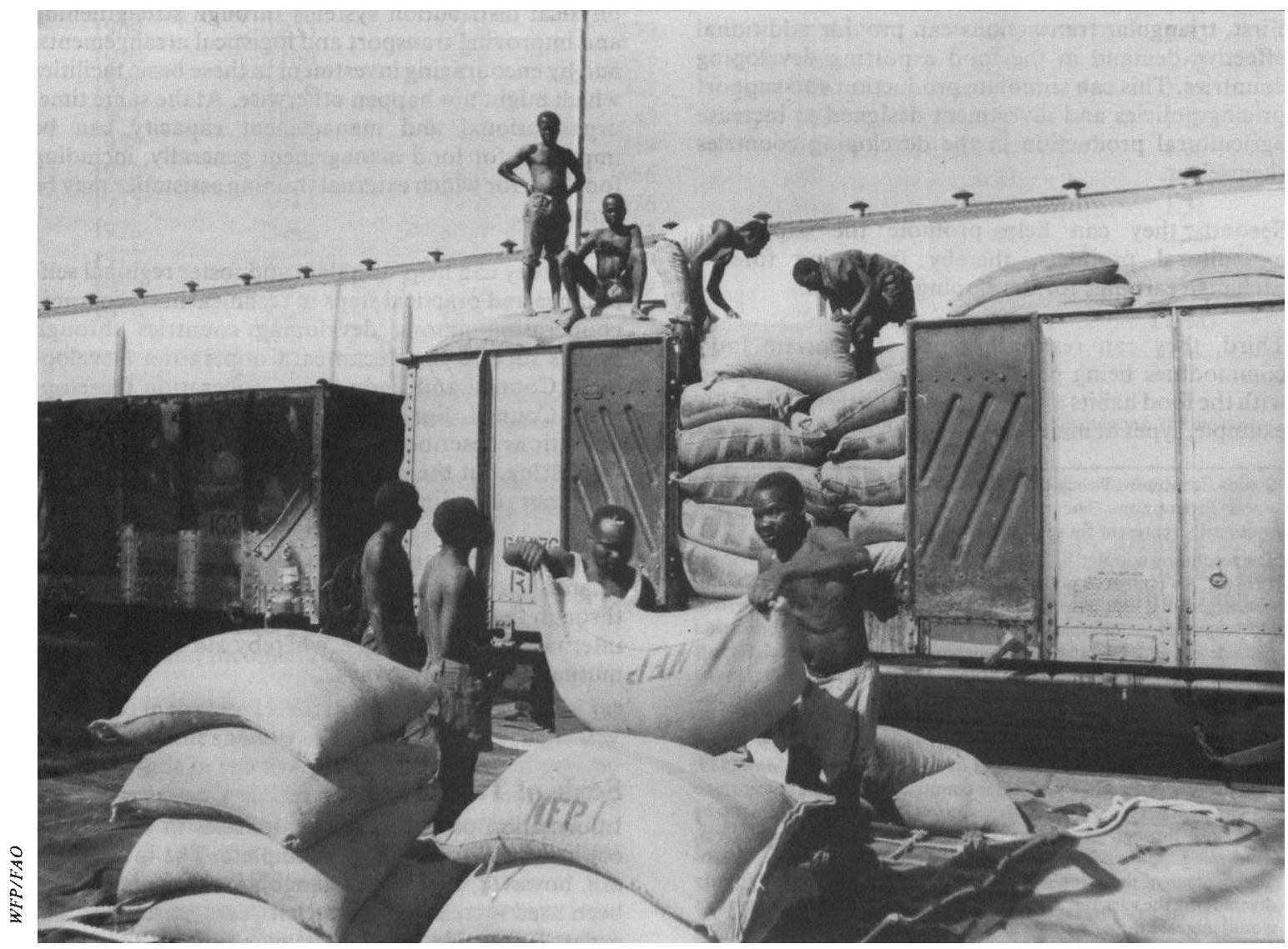

Zimbabwe maize train. 
acute food shortages and when the Programme was being increasingly called upon to provide both emergency and development assistance to alleviate the precarious food supply situation. It also occurred when WFP was endeavouring to implement triangular food supply arrangements wherever possible, in common with donor countries.

Since purchases began in June 1981, WFP has arranged for the purchase of 300,000 tons of maize in Zimbabwe. Purchases have been made not only with WFP's own cash resources but also through triangular transactions with cash provided by 16 donor countries and organisations (Algeria, Austria, Belgium, Denmark, Federal Republic of Germany, Finland, Italy, Japan, Netherlands, Norway, Sweden, Switzerland, the United Kingdom, the EEC, the OPEC Fund for International Development, the Kuwait Fund for Arab Economic Development) and some nongovernmental organisations, either through WFP or bilaterally, or out of their contributions to the IEFR.

The Zimbabwean maize purchased is being deployed as grant food aid in support of development projects, mainly for food and agricultural production and rural development, and for emergency operations, in 15 African countries (Angola, Benin, Botswana, Cape Verde, Chad, Kenya, Mali, Mozambique, Niger, Senegal, Somalia, Swaziland, Tanzania, Upper Volta and Zambia).

All purchases of maize have been obtained from the Zimbabwean Grain Marketing Board (GMB), the sole buyer and seller in the country. The prices paid for this maize have been under constant review to reflect changes in regional and world market prices. Moreover, in view of the humanitarian nature of WFP activities, GMB has sold the maize to the Programme at concessional prices. The white maize obtained is readily acceptable to the beneficiaries in contrast to the yellow maize previously donated as food aid which had to be mixed with that obtained from local production.

WFP has not only been engaged in purchasing maize in Zimbabwe but has also helped in the improvement of logistical arrangements. A major effort was required to reconstruct the transport and communications network, particularly through Mozambique to the coast, which had been destroyed during the war years. WFP was able to obtain the cooperation of a number of donor countries to do this. The building of storage units at strategic points, the construction of rain shelters, the surveys carried out on alternative routes to transport the maize through Mozambique to the coast and by land to Zambia, and the stationing of experienced transport coordinators in the field reinforced by periodic visits by headquarters personnel have all contributed to improving the transportation and logistics network.

In addition to providing cash for the purchase of maize, a number of donors have responded to WFP's request for complementary assistance in terms of expertise as well as in cash and kind. The Netherlands, Sweden and Switzerland have provided logistics expertise for Mozambique. France, the Netherlands and Norway have also provided cash contributions for such vitally needed equipment as a shunting tractor, conveyor stackers, stitching machines for bagging operations, tarpaulin and rain shelters as well as other miscellaneous items.

\section{Conclusions}

The regional approach to the planning and use of food aid, as reflected in the Zimbabwe maize operations, offers a number of advantages which can become increasingly important for food aid in the 1980s.

The CFA underlined the advantages to be gained from purchasing commodities in developing countries for food aid at its thirteenth session in April 1982. It appealed to donors to make cash available for triangular transactions which should enable WFP to carry out operations similar to those in Zimbabwe in other parts of the world, where appropriate. As grawing commitments to food production enable more developing countries to generate surpluses, WFP hopes to be able to undertake triangular transactions on an increasing scale. To repeat the Zimbàbwe experience elsewhere will not necessarily be easy. Food production in developing countries is uncertain and surpluses irregular and unpredictable. The size and quality of surplus production also present their own difficulties. Care will be needed in making purchases through triangular transactions not adversely to affect the internal market. Again, a physical distribution and transport system which can respond rapidly to new opportunities for exports may be lacking, where there is no regular tradition of commercial food exporting.

The WFP nevertheless intends to use its experience to obtain the maximum benefits from triangular transactions in the future. Such transactions are a concrete and striking way of promoting economic cooperation among developing countries. They also represent an outstanding example of active cooperation between a multilateral organisation, WFP, and developed and developing countries. WFP exists to promote the development, and to serve the humanitarian needs, of developing countries. It can also make a powerful contribution to international cooperation.

For references see page 61 . 